\title{
Influence of fluvastatin on cardiac function and baroreflex sensitivity in diabetic rats
}

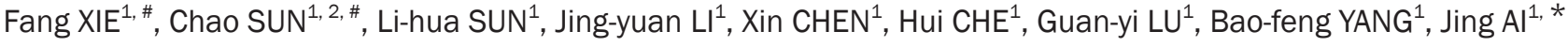 \\ ${ }^{1}$ Department of Pharmacology, and the State-Province Key Laboratory of Biomedicine and Pharmaceutics, Harbin Medical University, \\ Harbin 150081, China; ²Department of Pharmacology, Qiqihaer Medical College, Qiqihaer 161006, China
}

\begin{abstract}
Aim: To investigate whether fluvastatin is able to ameliorate the impaired cardiac function or baroreflex sensitivity (BRS) in rats with type 1 diabetes.

Methods: Type 1 diabetic rats were induced by intraperitoneal injection of streptozotocin (STZ) and then administered fluvastatin (1.5, 3.0, and $6.0 \mathrm{mg}^{\mathrm{kg}} \mathrm{kg}^{-1} \cdot \mathrm{d}^{-1}$ ) for $30 \mathrm{~d}$. Food and drink intake was recorded every day. Fasting blood glucose (FBG) level, blood lipid level, cardiac function and BRS were measured in diabetic rats after fluvastatin treatment for $30 \mathrm{~d}$.

Results: The polydipsia, polyphagia and abnormal biochemical indexes of blood were significantly ameliorated by the the 3.0- and 6.0$\mathrm{mg}$ doses of fluvastatin in STZ-induced diabetic rats. FBG was decreased in diabetic rats after fluvastatin treatment for $30 \mathrm{~d}$. The left ventricular systolic pressure (LVSP) and the maximum rate of change of left ventricular pressure in the isovolumic contraction and relaxation period $\left( \pm \mathrm{dp} / \mathrm{d} t_{\max }\right)$ were elevated, and left ventricular diastolic pressure (LVEDP) was decreased by fluvastatin. The attenuated heart rate responses to arterial blood pressure (ABP) increase induced by phenylephrine (PE) and ABP decrease induced by sodium nitroprusside (SNP) were reversed by the 3.0-mg dose of fluvastatin.

Conclusion: Fluvastatin regulates blood lipid levels and decreases the FBG level in diabetic rats. These responses can protect the diabetic heart from complications by improving cardiac function and BRS.
\end{abstract}

Keywords: fluvastatin; diabetes; cardiac function; baroreflex sensitivity

Acta Pharmacologica Sinica (2011) 32: 321-328; doi: 10.1038/aps.2010.221

\section{Introduction}

Diabetic heart complications influence the prognosis of patients and are the main reason for the high mortality of diabetic patients ${ }^{[1]}$. A number of studies have reported that diabetes mellitus (DM) leads to autonomic neuropathic dysfunctions, including impairment of the baroreflex control of heart rate $(\mathrm{HR})$ in both diabetic patients and chemically induced diabetic rats ${ }^{[2,3]}$. Impairment of the baroreflex sensitivity (BRS) underlying the diabetic state was closely related to lifethreatening arrhythmias, heart failure and sudden death ${ }^{[4,5]}$. Hypoglycemic agents, such as thiazolidinediones (TDs), which are the most common drugs used for DM, mainly ameliorate insulin resistance and regulate lipid metabolism. Therefore, it is necessary to find drugs that will relieve the impairment of BRS to prevent further cardiac complications in diabetic patients.

\footnotetext{
\# The first two authors contributed equally to this work.

* To whom correspondence should be addressed.

E-mail a.z.hrbmu@gmail.com

Received 2010-08-17 Accepted 2010-12-02
}

It is known that inhibition of 3-hydroxy-3-methylglutaryl coenzyme A (HMG-CoA), the rate-limiting enzyme in cholesterol synthetic pathways, will reduce the release of cholesterol into the blood in the form of very low density lipoprotein ${ }^{[6]}$. Fluvastatin, an HMG-CoA reductase inhibitor, which is the first wholly synthetic statin on the market, has been widely used as a classic lipid-regulating drug to treat hypercholesterolemia $^{[7]}$. The advantages of fluvastatin, compared to other statins, are as follows: fluvastatin is well tolerated ${ }^{[8,9]}$, substantial benefits of fluvastatin have been confirmed in clinical trials $^{[10]}$, and fluvastatin is more cost effective for long-term treatment ${ }^{[11]}$. Beyond its regulation of blood lipids, the antiatherogenic, antithrombotic and antioxidative actions of fluvastatin have been used to prevent cardiovascular disease ${ }^{[12]}$. As shown in previous studies, fluvastatin was found to reduce the increased incidence of long-term adverse complications associated with diabetes ${ }^{[13]}$. Other roles of fluvastatin in diabetic treatment have also been reported, such as ameliorating cardiac sympathetic neural dysfunction in association with the attenuation of increased myocardial oxidative stress; preventing left ventricular remodeling by reducing myocardial fibro- 
sis; exerting a protective action on vascular endothelial cells; and protecting against oxidative DNA damage ${ }^{[14,15]}$. Although various functions of fluvastatin have been studied in the treatment of diabetes, whether it plays a role in ameliorating impaired BRS is unknown.

In this work, the BRS measured with baroreflex control of $\mathrm{HR}$ and other parameters, biochemical indexes of blood and cardiac function were examined in streptozotocin (STZ)induced diabetic rats to evaluate the effects of fluvastatin. We found that fluvastatin could effectively preserve impaired BRS in diabetic rats. Moreover, it shows promise in the development of improved drugs to address the adverse cardiac complications associated with diabetes.

\section{Materials and methods Chemicals}

Fluvastatin was purchased from Novartis Pharma (Beijing, China). STZ was obtained from Sigma-Aldrich (St Louis, MO, USA). Adrenaline was obtained from Shanghai Harvest Pharmaceutical Co, Ltd (Shanghai, China). Sodium nitroprusside was acquired from Shanghai № 1 Biochemical and Pharmaceutical Co, Ltd (Shanghai, China). All other chemicals were of analytical grade from local suppliers.

\section{Animals}

Male Wistar rats ( $n=34$, weight $220-260 \mathrm{~g}$, age approximately 3-4 months) were obtained from the Animal Center of the Second Affiliated Hospital of Harbin Medical University (Harbin, China) and housed at $23 \pm 1{ }^{\circ} \mathrm{C}$ with $55 \% \pm 5 \%$ humidity and a 12-h light-dark cycle. The use of these animals was in accordance with the regulations of the Ethics Committees of Harbin Medical University (№ HMUIRB-2008-06).

\section{Establishment of a diabetic model}

DM was induced in the 28 randomly chosen rats by intraperitoneal (ip) injection of $40 \mathrm{mg} \cdot \mathrm{kg}^{-1}$ of streptozocin (STZ) in a $0.1 \mathrm{~mol} \cdot \mathrm{L}^{-1}$ citrate buffer solution ( $\mathrm{pH} 4.2$ ) each day for $2 \mathrm{~d}$ after fasting for $12 \mathrm{~h}$. The FBG level was measured using a Grace glucometer (Grace Medical, Inc, USA) from the tail vein $72 \mathrm{~h}$ after the final injection of STZ. Twenty-four of the STZinduced rats with a FBG $\geq 16.7 \mathrm{~mm}$ were used as established DM models.

\section{Group treatment}

Twenty-four rats with DM were randomly divided into four groups with six rats per group as follows: diabetes mellitus $(\mathrm{DM}), \mathrm{DM}$ with a high dose of fluvastatin $\left(6.0 \mathrm{mg} \cdot \mathrm{kg}^{-1} \cdot \mathrm{d}^{-1}\right)$ $(\mathrm{DM}+\mathrm{FH}), \mathrm{DM}$ with a middle dose of fluvastatin (3.0 $\left.\mathrm{mg} \cdot \mathrm{kg}^{-1} \cdot \mathrm{d}^{-1}\right)(\mathrm{DM}+\mathrm{FM})$ and DM with a low dose of fluvastatin $\left(1.5 \mathrm{mg} \cdot \mathrm{kg}^{-1} \cdot \mathrm{d}^{-1}\right)(\mathrm{DM}+\mathrm{FL})$. Fluvastatin was intragastrically administered for $30 \mathrm{~d}$ after confirmation of DM with the different doses described previously. The other six healthy Wistar rats were used as a control group (Ctr) and were treated with the same quantity of vehicle (citrate buffer) and $0.9 \% \mathrm{NaCl}$.

\section{Measurement of food and drink intake}

From the beginning of fluvastatin administration, the food and drink intake for all animals was recorded every $24 \mathrm{~h}$ for $30 \mathrm{~d}$. The average food and drink intake for each group was determined by dividing the total amount of food and drink consumed by the total number of rats in each group.

\section{Biochemical indexes of blood}

After $30 \mathrm{~d}$ of fluvastatin treatment, the FBG level was measured from the tail vein using a Grace glucometer after a fasting period of $12 \mathrm{~h}$. Following cardiac function and BRS studies, blood samples were collected from the heart and then separated to analyze for total cholesterol (TC), triglycerides (TG), low-density lipoprotein (LDL), high-density lipoprotein (HDL), free fatty acids (FFA) and malondialdehyde (MDA), using the appropriate kit (Shanghai Rongsheng Biotech Co, Ltd, China) for each test.

\section{In vivo cardiac function studies}

After determination of FBG level from the tail vein, all rats from each group were anesthetized with sodium pentobarbital $\left(40 \mathrm{mg} \cdot \mathrm{kg}^{-1}\right)$ via ip injection. Cardiac function was calculated as previously described ${ }^{[16]}$; briefly, the catheter was inserted into the left ventricle via the right common carotid artery to record cardiac electrophysiologic parameters. Arterial blood pressure $(\mathrm{ABP})$, heart rate (HR), left ventricular systolic pressure (LVSP), left ventricular diastolic pressure (LVEDP) and the maximum rate of change in left ventricular pressure in the isovolumic contraction or relaxation period $\left( \pm \mathrm{d} p / \mathrm{d} t_{\max }\right)$ were measured using a BL-420 Data Acquisition \& Analysis System (Chengdu Tme Technology Co, Ltd, China).

\section{Surgical procedure}

After cardiac function studies were completed, the surgery proceeded on all rats from the Ctr, DM and DM+FM groups. These rats were anesthetized with an ip injection of sodium pentobarbital $\left(40 \mathrm{mg} \cdot \mathrm{kg}^{-1}\right)$. The surgical procedure was in accordance with previous studies ${ }^{[17-19]}$. Briefly, supplemental doses of anesthetics ( $0.1 \mathrm{~mL}$ of $1 \%$ sodium pentobarbital) were administered every 30 min to prevent eye blinking and pedalwithdrawal reflexes. The tips of polyethylene-50 catheters were tapered to a diameter of $0.5 \mathrm{~mm}$. After the exposure of the femoral artery (left) and the femoral vein (right), the tapered tips of two catheters filled with heparinized saline were then inserted into the femoral artery and vein. Vasoactive drugs were injected into the femoral vein, and blood pressure was measured in the femoral artery.

\section{Baroreflex sensitivity}

The blood pressure catheter was connected to a blood pressure transducer (MIT0699; AD Instruments, Australia) placed in a horizontal position level with the heart. ABP was measured automatically using the BL-420 Data Acquisition \& Analysis System. HR was calculated from pulse pressures using the Ratemeter function. Phenylephrine (PE) or sodium nitroprus- 
side (SNP) was injected at various dosage levels (PE: 16, 32, 64, 128, and $256 \mu \mathrm{g} \cdot \mathrm{mL}^{-1}$; SNP: $10,20,40,80$, and $\left.160 \mu \mathrm{g} \cdot \mathrm{mL}^{-1}\right)$ with an injection speed of $0.04 \mathrm{~mL} \cdot 100 \mathrm{mg}^{-1}$. A second drug administration was not performed until the HR and ABP responses reached a steady-state response. The maximal $H R$ responses relative to the HR baseline level $(\triangle \mathrm{HR})$ and mean $\mathrm{ABP}(\mathrm{MABP})$ changes relative to the $\mathrm{ABP}$ baseline level $(\triangle \mathrm{MABP})$ induced by injection of PE or SNP were recorded and analyzed. The averaged ratio of the HR change over the MABP change $(\triangle \mathrm{HR} / \triangle \mathrm{MABP})$ was used to evaluate the baroreflex sensitivity (BRS) for each dose of each drug given. Dose-dependent curves for $\triangle \mathrm{MABP}$ and $\triangle \mathrm{HR} / \triangle \mathrm{MABP}$ as functions of $\mathrm{PE}$ and SNP concentration were plotted for each group. Curves of $\triangle \mathrm{HR}-\triangle \mathrm{MABP}$ were also plotted to display the maximal $\mathrm{HR}$ responses induced by MABP changes. The Boltzmann equation in Prism 5.0 software (GraphPad Software Inc, San Diego, CA, USA) was used to fit all curves ${ }^{[17,20]}$.

\section{Statistical analysis}

Data were analyzed using one-way ANOVA, and $P<0.05$ was considered statistically significant. Data were expressed as mean \pm SEM. Different baseline MABP and HR were compared for the divided groups using Student's $t$-tests.

\section{Results}

\section{Effects of fluvastatin on food and drink intake}

After the initial fluvastatin administration, the average food and drink consumption for rats in each group were recorded each day (Figure 1). The results demonstrate that both food and drink consumptions were greatly increased in the diabetic rats until a steady dose-dependent decrease in consumption occurred after approximately $12 \mathrm{~d}$ of fluvastatin treatment in DM rats. Polydipsia and polyphagia were remarkably improved in the $\mathrm{DM}+\mathrm{FM}$ and $\mathrm{DM}+\mathrm{FH}$ groups $(P<0.05)$.

\section{Effects of fluvastatin on biochemical indexes of blood}

Thirty days after the establishment of the STZ-induced DM rats, TC, TG, LDL, FBG, FFA, and MDA were significantly increased, while HDL was decreased (Table 1). This suggests that after $30 \mathrm{~d}$ of treatment, fluvastatin effectively improved TC, TG, HDL, LDL, and FBG in a dose-dependent manner.
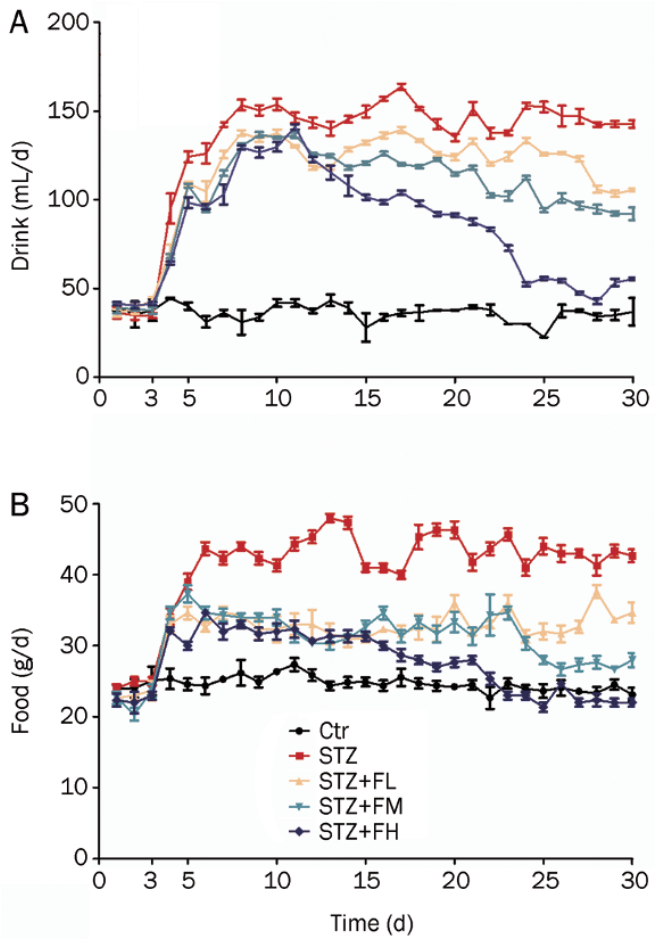

Figure 1. Drink and food intake versus time after fluvastatin administration in the four groups: streptozotocin (STZ)-induced diabetes mellitus (DM) rats, DM rats with low-dose fluvastatin $(D M+F L)$, middledose fluvastatin $(\mathrm{DM}+\mathrm{FM})$ and high-dose fluvastatin $(\mathrm{DM}+\mathrm{FH})$ treatment. (A) Changes of drink intake of rats in the four groups. (B) Changes of food intake of rats in the four groups. STZ-induced DM rats significantly increased both drink and food consumptions while DM rats with fluvastatin treatment had a steady dose-dependent downward trend of drink and food intake $(n=6)$.

However, only slight changes in FFA and MDA were observed in all of the groups.

\section{Effects of fluvastatin on cardiac function}

The LVSP was significantly decreased in the DM group compared with the Ctr group (Figure $2 \mathrm{~A} ; 14.87 \pm 0.25 \mathrm{kPa}$ and $11.63 \pm 0.22 \mathrm{kPa}$ for $\mathrm{Ctr}$ rats and DM rats, respectively;

Table 1. The effect of fluvastatin on biochemical indexes of blood in diabetic rats $(n=6)$. Ctr: control group; DM: diabetic group; DM+FL: DM with lowdose fluvastatin $\left(1.5 \mathrm{mg} \cdot \mathrm{kg}^{-1} \cdot \mathrm{d}^{-1}\right)$; DM+FM: DM with middle-dose fluvastatin $\left(3.0 \mathrm{mg} \cdot \mathrm{kg}^{-1} \cdot \mathrm{d}^{-1}\right)$; DM+FH: DM with high-dose fluvastatin $\left(6.0 \mathrm{mg} \cdot \mathrm{kg}^{-1} \cdot \mathrm{d}^{-1}\right)$. Mean \pm SEM. ${ }^{b} P<0.05,{ }^{c} P<0.01$ vs control group; ${ }^{f} P<0.05$ vs diabetic group.

\begin{tabular}{|c|c|c|c|c|c|c|c|}
\hline Groups & $\mathrm{TC}(\mathrm{mmol} / \mathrm{L})$ & $\mathrm{TG}(\mathrm{mmol} / \mathrm{L})$ & $\mathrm{HDL}(\mathrm{mmol} / \mathrm{L})$ & LDL (mmol/L) & $\mathrm{FBG}(\mathrm{mmol} / \mathrm{L})$ & FFA (nmol/L) & $\operatorname{MDA}(\mathrm{nmol} / \mathrm{L})$ \\
\hline Ctr & $1.19 \pm 0.05$ & $0.37 \pm 0.03$ & $0.52 \pm 0.02$ & $0.44 \pm 0.03$ & $5.23 \pm 0.12$ & $0.55 \pm 0.04$ & $5.25 \pm 0.21$ \\
\hline DM & $1.24 \pm 0.02^{b}$ & $0.51 \pm 0.02^{b}$ & $0.32 \pm 0.02^{b}$ & $0.53 \pm 0.02^{b}$ & $21.95 \pm 3.92^{c}$ & $1.10 \pm 0.06^{b}$ & $8.42 \pm 0.41^{b}$ \\
\hline $\mathrm{DM}+\mathrm{FM}$ & $1.21 \pm 0.04$ & $0.40 \pm 0.02^{f}$ & $0.44 \pm 0.02^{f}$ & $0.42 \pm 0.01^{f}$ & $14.15 \pm 1.34^{\mathrm{bf}}$ & $0.76 \pm 0.03^{b}$ & $6.32 \pm 0.33^{b}$ \\
\hline $\mathrm{DM}+\mathrm{FH}$ & $1.21 \pm 0.05$ & $0.39 \pm 0.03^{f}$ & $0.47 \pm 0.01^{\dagger}$ & $0.41 \pm 0.02^{f}$ & $9.42 \pm 1.28^{b f}$ & $0.64 \pm 0.02^{b}$ & $5.86 \pm 0.29^{b}$ \\
\hline
\end{tabular}

TC, total cholesterol; TG, triglyceride; HDL, high density lipoprotein; LDL, low density lipoprotein; FBG, fasting blood glucose; FFA, free fatty acids; MDA, malondialdehyde. 

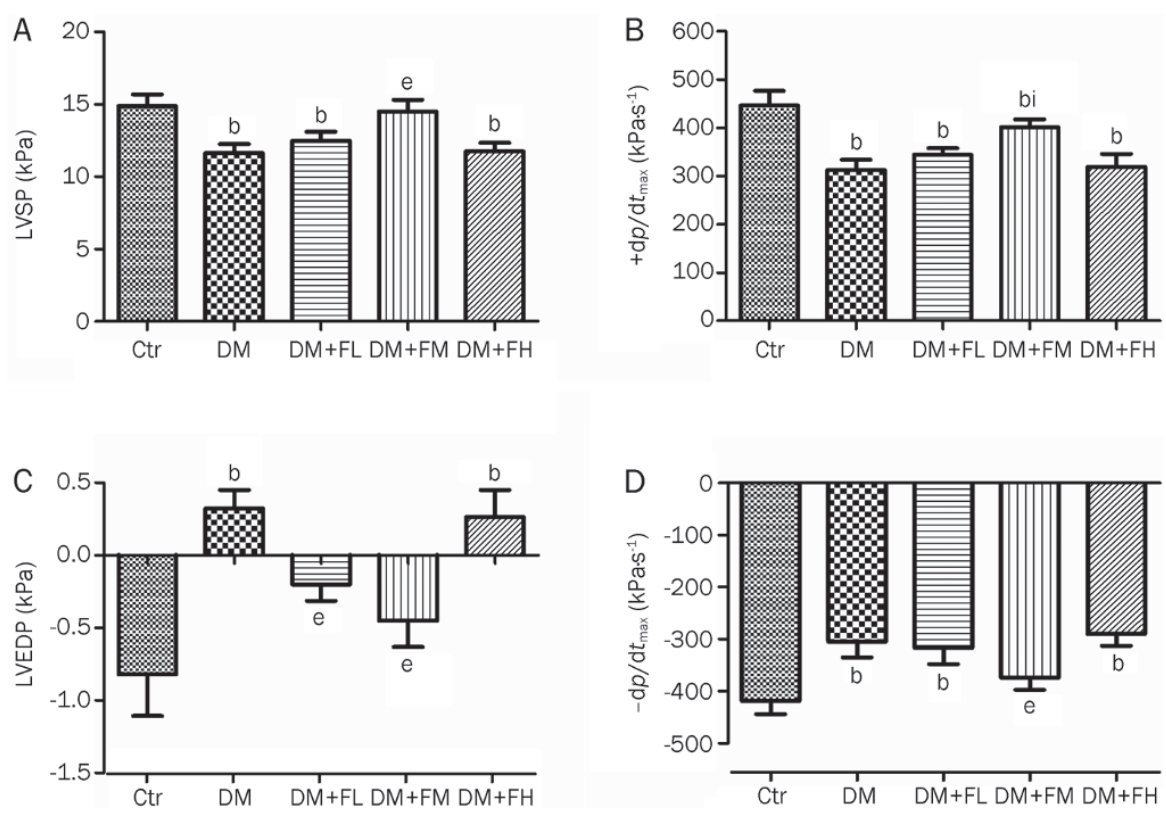

Figure 2. Quantitative analysis of parameters of cardiac function in control rats (Ctr), streptozotocin (STZ)-induced diabetes mellitus (DM) rats, $\mathrm{DM}$ rats with low-dose fluvastatin $(\mathrm{DM}+\mathrm{FL})$, middle-dose fluvastatin (DM+FM) and high-dose fluvastatin $(\mathrm{DM}+\mathrm{FH})$. (A) left ventricular systolic pressure (LVSP); (B) maximum change velocity of left ventricular pressure in the isovolumic contraction period $\left(+\mathrm{d} p / \mathrm{d} t_{\max }\right)$; (C) left ventricular diastolic pressure (LVEDP); (D) maximum change velocity of left ventricular pressure in the isovolumic relaxation period $\left(-\mathrm{d} p / \mathrm{d} t_{\max }\right) .{ }^{\mathrm{b}} \mathrm{P}<0.05$ vs Ctr; ${ }^{\mathrm{e}} \mathrm{P}<0.05,{ }^{\mathrm{i}} \mathrm{P}<0.01$ vs $\mathrm{DM}(n=6)$.
$P<0.05)$. This effect was offset by the middle dose of fluvastatin $(14.49 \pm 0.39 \mathrm{kPa} ; P<0.05)$; however, neither the low dose $(12.50 \pm 0.29 \mathrm{kPa} P>0.05)$ nor the high dose $(11.76 \pm 0.27 \mathrm{kPa}$; $P>0.05)$ of fluvastatin improved LVSP.

As shown in Figure $2 \mathrm{~B}$, the decreased $+\mathrm{d} p / \mathrm{d} t_{\max }$ in $\mathrm{DM}$ rats was increased following treatment with the middle dose of fluvastatin for $30 \mathrm{~d}\left(446.00 \pm 9.21 \mathrm{kPa} \cdot \mathrm{s}^{-1}\right.$ for the Ctr rats, $312.89 \pm 8.00 \mathrm{kPa} \cdot \mathrm{s}^{-1}$ for the DM rats and $401.11 \pm 6.21 \mathrm{kPa} \cdot \mathrm{s}^{-1}$ for the $\mathrm{DM}+\mathrm{FM}$ rats; $P<0.05$ ), but this effect was not seen in the $\mathrm{DM}+\mathrm{FL}$ or the $\mathrm{DM}+\mathrm{FH}$ group $\left(344.22 \pm 5.08 \mathrm{kPa} \cdot \mathrm{s}^{-1}\right.$ for the $\mathrm{DM}+\mathrm{FL}$ rats and $319.56 \pm 9.98 \mathrm{kPa} \cdot \mathrm{s}^{-1}$ for the $\mathrm{DM}+\mathrm{FH}$ rats; $P>0.05)$.

LVEDP sharply increased in the DM rats $(0.32 \pm 0.05 \mathrm{kPa})$ compared with the Ctr rats $(-0.82 \pm 0.08 \mathrm{kPa} ; P<0.05)$. As shown in Figure 2C, LVEDP in the DM+FL $(-0.20 \pm 0.04 \mathrm{kPa})$ and $\mathrm{DM}+\mathrm{FM}(-0.45 \pm 0.07 \mathrm{kPa})$ rats experienced a substantial decrease compared with the DM rats $(P<0.05)$. However, the $\mathrm{DM}+\mathrm{FH}$ rats did not show significant improvement in LVEDP $(0.26 \pm 0.07 \mathrm{kPa} ; P>0.05)$.

The $-\mathrm{d} p / \mathrm{d} t_{\max }$ an indicator of diastolic function, was significantly impaired in the DM rats compared with the Ctr rats (Figure 2D; $-418.88 \pm 10.13 \mathrm{kPa} \cdot \mathrm{s}^{-1}$ for the $\mathrm{Ctr}$ rats and $-304.38 \pm 12.29 \mathrm{kPa} \cdot \mathrm{s}^{-1}$ for the DM rats; $\left.P<0.05\right)$. While the middle dose of fluvastatin successfully reversed this parameter to $-373.63 \pm 9.62 \mathrm{kPa} \cdot \mathrm{s}^{-1}(P<0.05)$, the low dose $(-316.75 \pm 12.38$ $\left.\mathrm{kPa} \cdot \mathrm{s}^{-1}\right)$ and the high dose $\left(-290.13 \pm 9.08 \mathrm{kPa} \cdot \mathrm{s}^{-1}\right)$ of fluvastatin did not have the same effect $(P>0.05)$.

\section{Baroreflex control of heart rate during phenylephrine admini-} stration

MABP was gradually raised by doses of PE in the Ctr, DM, and $\mathrm{DM}+\mathrm{FM}$ rats (Figure $3 \mathrm{~A}, 3 \mathrm{~B}$, and $3 \mathrm{C}$ ). Meanwhile, the dose-dependent curves used to assess the maximal $\triangle \mathrm{MABP}$ over various PE doses are shown in Figure 3D. The magnitude of the increase in $\triangle \mathrm{MABP}$ following PE injection appeared less significant for all doses in the DM rats when compared to the Ctr rats $(P<0.05)$; this is consistent with previous studies ${ }^{[20,21]}$. This decrease was dramatically alleviated in the DM+FM rats $(P<0.05)$. For example, the $256 \mu \mathrm{g} \cdot \mathrm{mL}^{-1}$ dose of PE caused the $\triangle \mathrm{MABP}$ to collapse to $29.42 \pm 3.54 \mathrm{mmHg}$ in the DM rats compared with $48.99 \pm 3.79 \mathrm{mmHg}$ in the Ctr rats $(P<0.05)$, and it was greatly improved to $43.61 \pm 4.46 \mathrm{mmHg}$ in the DM+FM rats $(P<0.05)$.

To estimate the BRS, the $\triangle \mathrm{HR} / \triangle \mathrm{MABP}$ ratio was depicted as an index. As shown in Figure 3E, with the increase in the $\mathrm{PE}$ dose, the $\triangle \mathrm{HR} / \triangle \mathrm{MABP}$ displayed an increasing trend for all of the groups, although the margins of the increases varied. Of note, the $\triangle \mathrm{HR} / \triangle \mathrm{MABP}$ value was significantly increased in the DM rats as compared to the Ctr rats at every dosage level of PE $(P<0.05)$. The middle dose of fluvastatin caused the variation to diminish $(P<0.05)$. For instance, at the dose of $256 \mu \mathrm{g} \cdot \mathrm{mL}^{-1}$ of PE, the middle dose of fluvastatin reversed the increased $\triangle \mathrm{HR} / \triangle \mathrm{MABP}$ value from $2.22 \pm 0.11$ beats $\cdot \mathrm{min}^{-1} \cdot \mathrm{mmHg}^{-1}$ in the DM rats to $1.91 \pm 0.13$ beats $\cdot \mathrm{min}^{-1} \cdot \mathrm{mmHg}^{-1}$ in the $\mathrm{DM}+\mathrm{FM}$ rats; this was a partial recovery when compared with the Ctr rats $(1.74 \pm 0.11$ beats $\cdot \mathrm{min}^{-1} \cdot \mathrm{mmHg}^{-1}$ ).

The maximal HR responses at steady state to the maximal changes of MABP induced by different doses of PE and $\triangle H R$ were plotted as functions of $\triangle \mathrm{MABP}$ (Figure $3 \mathrm{~F}$ ). The curves were fit using the Boltzmann equation after maximal $\triangle H R$ and $\triangle \mathrm{MABP}$ were averaged at the different PE doses within each group $^{[22]}$. As expected, the maximal $\Delta H R$ in response to the maximal $\triangle \mathrm{MABP}$ was reduced in the $\mathrm{DM}$ rats $(31.42 \mathrm{mmHg})$ compared with the Ctr rats $(43.98 \mathrm{mmHg})$, and this reduction could also be seen in the DM+FM rats $(40.58 \mathrm{mmHg})$.

Baroreflex control of heart rate during sodium nitroprusside administration

The decrease of MABP was induced by SNP in a dose-depen- 


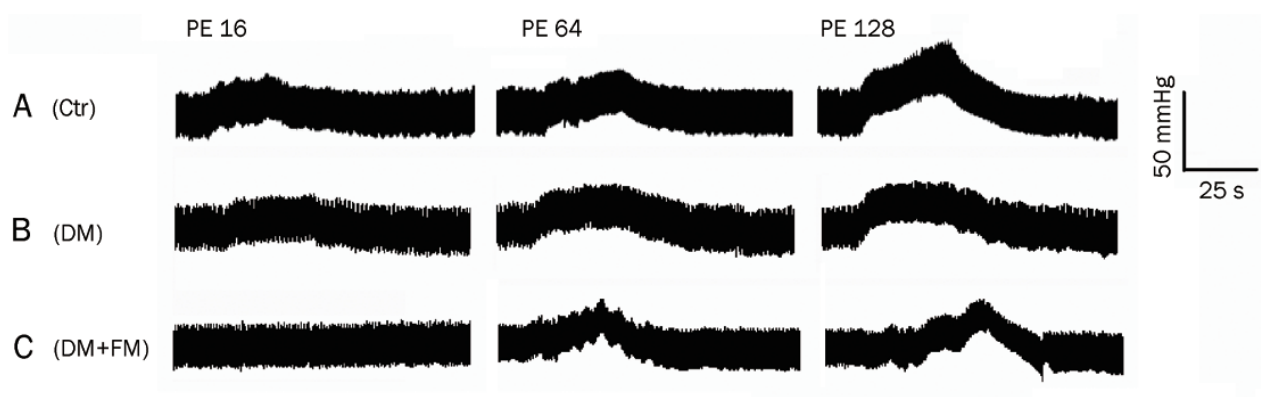

D

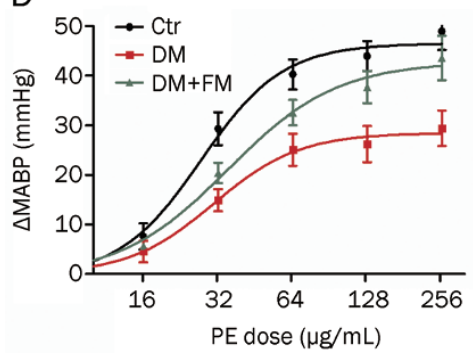

E

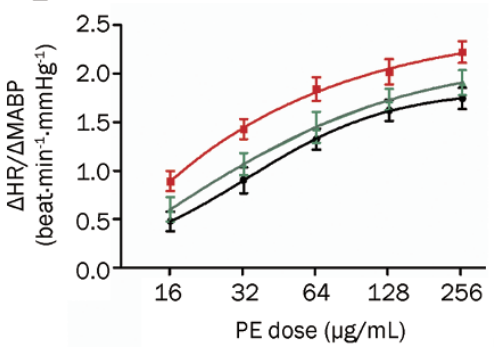

F
$40.58 \mathrm{mmHg}$

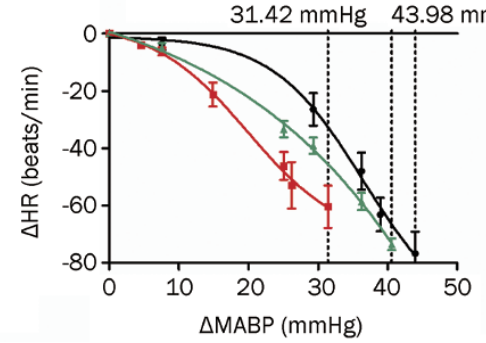

Figure 3. Significant amelioration of impaired baroreflex sensitivity in streptozotocin (STZ)-induced diabetes mellitus (DM) rats after 30-d treatment with middle-dose fluvastatin following phenylephrine (PE) administration. Traces of blood pressure changes induced by PE application at 16, 64, and 128 $\mathrm{\mu g} / \mathrm{mL}$ in (A) control rats (Ctr), (B) STZ-induced DM rats (DM) and (C) DM rats with middle-dose fluvastatin (DM+FM). (D) The curve of change in mean arterial blood pressure ( $\triangle \mathrm{MABP}$ ) against each dose of $\mathrm{PE}$ in the three groups. (E) The curve of $\triangle \mathrm{HR} / \triangle \mathrm{MABP}$ against different doses of PE in the three groups. $(F)$ The curve of $\triangle \mathrm{HR}$ against $\triangle \mathrm{MABP}$ in the three groups. Values are means $(n=6)$ with standard errors represented by vertical bars.

dent manner for the Ctr, the DM and the DM+FM rats, as shown in Figure $4 \mathrm{~A}, 4 \mathrm{~B}$, and $4 \mathrm{C}$. Furthermore, the $\triangle \mathrm{MABP}$ dose-dependent curve in the DM and the DM+FM rats for each dose of SNP appeared similar to that of the PE curves. The $\triangle \mathrm{MABP}$ was decreased in the DM rats compared with the Ctr rats, and this decrease was partly recovered by adminis-

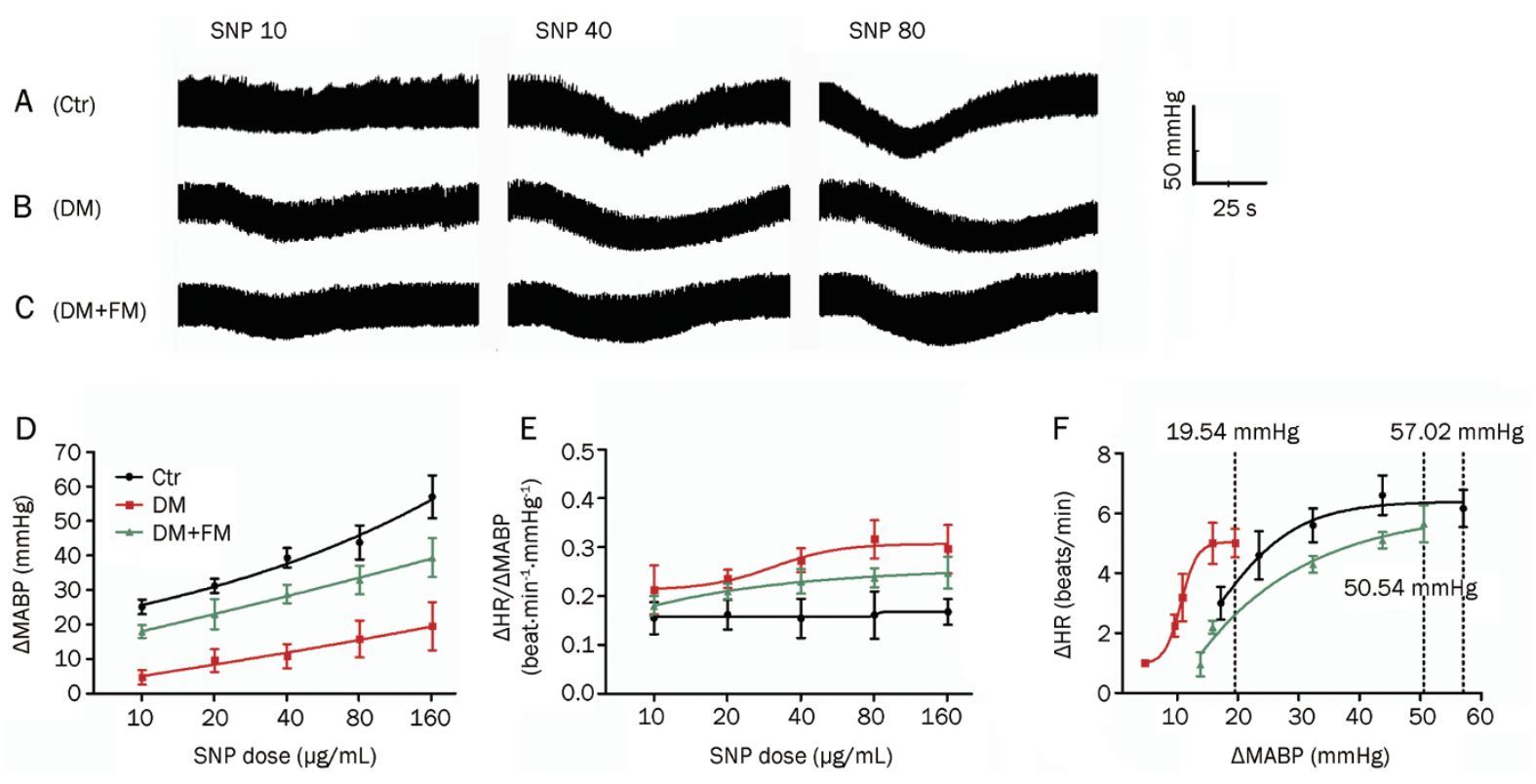

Figure 4. Effects of middle-dose fluvastatin on baroreflex sensitivities of rats with diabetes mellitus (DM) induced by streptozotocin (STZ) during sodium nitroprusside (SNP) application. Traces of blood pressure changes induced by SNP application at 10, 40, and $80 \mu \mathrm{g} / \mathrm{mL}$ in (A) control rats (Ctr), (B) STZ-induced DM rats (DM) and (C) DM rats with middle-dose fluvastatin (DM+FM). (D) The curve of change in mean arterial blood pressure ( $\triangle \mathrm{MABP}$ ) against different doses of SNP in the three groups. (E) The curve of $\triangle \mathrm{HR} / \triangle \mathrm{MABP}$ against different doses of SNP in the three groups. (F) The curve of $\triangle \mathrm{HR}$ against $\triangle \mathrm{MABP}$ in the three groups. Values are means $(n=6)$ with standard errors represented by vertical bars. 
tration of the middle-dose of fluvastatin (Figure 4D; $P<0.05$ ). This was fully demonstrated by the values at the SNP dose of $160 \mu \mathrm{g} \cdot \mathrm{mL}^{-1}(57.02 \pm 6.19 \mathrm{mmHg}$ for the Ctr rats; $19.54 \pm 6.97$ $\mathrm{mmHg}$ for the $\mathrm{DM}$ rats and $39.43 \pm 5.61 \mathrm{mmHg}$ for the DM+FM rats).

No significant changes in the $\triangle \mathrm{HR} / \triangle \mathrm{MABP}$ were noted in the Ctr rats, and only a slight increase in $\triangle \mathrm{HR} / \triangle \mathrm{MABP}$ was detected with the increase in SNP administered to the DM and the DM+FM rats (Figure $4 \mathrm{E}$ ). However, the $\triangle \mathrm{HR} / \triangle \mathrm{MABP}$ value was marginally increased with the same dose of SNP administered to the DM rats compared to the Ctr rats. Meanwhile, the $\triangle H R / \triangle M A B P$ value of the DM+FM rats was located between that of the other two groups. When $160 \mu \mathrm{g} \cdot \mathrm{mL}^{-1}$ of SNP was given to rats in all of the groups, the $\triangle \mathrm{HR} / \triangle \mathrm{MABP}$ increased from $0.17 \pm 0.03$ beats $\mathrm{min}^{-1} \cdot \mathrm{mmHg}^{-1}$ in the $\mathrm{Ctr}$ rats to $0.30 \pm 0.05$ beats $\cdot \mathrm{min}^{-1} \cdot \mathrm{mmHg}^{-1}$ in the DM rats and $0.25 \pm 0.03$ beats $\mathrm{min}^{-1} \cdot \mathrm{mmHg}^{-1}$ in the $\mathrm{DM}+\mathrm{FM}$ rats.

It should be noted that the response of the maximal $\Delta \mathrm{HR}$ to the maximal $\triangle \mathrm{MABP}$ displayed a sharp decrease in the DM rats $(19.54 \mathrm{mmHg})$ compared with the Ctr rats $(57.02 \mathrm{mmHg})$. Similarly, the middle dose of fluvastatin reversed this effect, resulting in a value of $50.54 \mathrm{mmHg}$ (Figure $4 \mathrm{~F}$ ).

\section{Discussion}

The type 1 diabetic model has been successfully established by the intraperitoneal injection of STZ in Wistar rats. Our studies have shown that food and drink consumption began to decrease in a dose-dependent manner in the DM rats after approximately $12 \mathrm{~d}$ of fluvastatin treatments, particularly in the DM+FM and the DM+FH groups. This phenomenon undoubtedly indicates that fluvastatin could ameliorate polydipsia and polyphagia, which are typical symptoms of DM.

As predicted, in the DM rats the levels of TC, TG, and LDL were significantly reduced, but the HDL level was increased by fluvastatin. However, the FFA and the MDA were slightly decreased by any dose of fluvastatin in the DM rats. These results demonstrate that fluvastatin can dramatically regulate blood lipid, and the mechanism has been well documented ${ }^{[6,}$ ${ }^{7]}$. These are the main reasons that fluvastatin is used to treat diabetic patients with hyperlipemia. The FBG level in the $\mathrm{DM}+\mathrm{FM}$ and the $\mathrm{DM}+\mathrm{FH}$ rats dropped significantly; however, the low dose of fluvastatin did not achieve this effect. It is reasonable to presume that regulating blood lipid and improving insulin sensitivity may contribute to the hypoglycemic effect of fluvastatin. Therefore, if the underlying mechanisms for the effect of fluvastatin identified in clinical trials could be determined, diabetic patients using fluvastatin would not only pay attention to its classic lipid-regulating effect but also benefit from its hypoglycemic action.

In this study, impaired cardiac function was confirmed in the DM rats by the following parameters: LVSP, LVEDP, and $\pm \mathrm{d} p / \mathrm{d} t_{\max }$. Nevertheless, fluvastatin could partially reverse the impairment of both contractile and diastolic functions in a dose-independent manner; however, the middle dose rather than the high dose of fluvastatin was significantly more effective in improving cardiac function in the DM rats. The
$\mathrm{DM}+\mathrm{FH}$ rats suffered severe rhabdomyolysis - toxicity of the skeletal muscle due to RhoA dysfunction following the loss of lipid modification with geranylgeranyl pyrophosphate ${ }^{[23,24]}$. Consequently, it was reasonable to presume that pain caused by severe rhabdomyolysis may contribute to the negative impact on cardiac function seen in the $\mathrm{DM}+\mathrm{FH}$ rats. It is known that primary myocardial defect and BRS impairment may both underlie the impaired cardiac function of diabetic patients. According to recent studies, fluvastatin can reduce myocardial fibrosis and exert a direct anti-atherosclerotic action on the arterial wall, which may improve cardiac function in an experimental model of diabetic cardiomyopathy ${ }^{[12]}$. All the facts addressed above may contribute to the amelioration of the primary myocardial defect that accompanies fluvastatin administration in DM rats. Consequently, it is important to determine whether fluvastatin could improve impaired BRS and lead to an improvement in cardiac function.

The optimal dose of fluvastatin is $6.0 \mathrm{mg} \cdot \mathrm{kg}^{-1} \cdot \mathrm{d}^{-1}$ (the middle dose) and was chosen for the BRS study based on the following observations: the middle dose of fluvastatin exerted the most obvious effect according to cardiac function analysis; the blood lipid and the FBG were significantly regulated in both the $\mathrm{DM}+\mathrm{FM}$ and the $\mathrm{DM}+\mathrm{FH}$ rats; the middle dose of fluvastatin was equal to the clinical dosage amount; and the $\mathrm{DM}+\mathrm{FH}$ rats suffered severe rhabdomyolysis, suggesting that clinical application of high-dose fluvastatin may result in severe side effects.

Our results showed that fluvastatin could reverse the decreased $\triangle \mathrm{MABP}$ caused by DM when various dosages of $\mathrm{PE}$ and SNP were administered. Interestingly, the increase of $\triangle \mathrm{HR} / \triangle \mathrm{MABP}$, an indicator of BRS, was greater in DM rats compared with Ctr rats in response to PE and SNP injections. This result is not consistent with those of some DM models, which may be largely attributed to the different time course of development for diabetes (ie, 12, 24, and 48 weeks): metabolic disorders caused by a hyperglycemic state or insulinopenia may be related to time-dependent changes in parasympathetic and sympathetic control ${ }^{[25,26]}$ and different osmotic diuresis after the DM model was established ${ }^{[27,28]}$. In addition, discrepancies in species, experimental design and diabetic inducer may also affect the results to some extent ${ }^{[29,}$ ${ }^{30]}$. However, our results are consistent with the findings of Jackson and colleagues ${ }^{[31]}$ that blood pressure responses to vasopressor agonists were depressed in STZ-induced DM rats while the baroreceptor reflexes in these rats were more sensitive to increases in blood pressure. Our experiments were similar to those of Jackson and colleagues in a number of ways, including HR changes to the altered arterial pressure (AP) used to evaluate the BRS of the STZ-induced short-term DM rates used in both studies. As the variable factors above lead to different BRSs, yet were equal in these two studies, the identical changes of BRS testify to the reliability of our study. Of note, the authors examined the BRS in the conscious state rather than in the anesthetized state as we did in our study. Previous studies have used conscious animals because anesthesia inhibits the baroreflex function and causes difficulties 
in recording changes of the BRS under different stimuli ${ }^{[32,33]}$. In our study, despite the possible inhibition of the baroreflex function caused by anesthesia, changes of the BRS were still obvious following various doses of injected PE and SNP. Furthermore, the comparison of our results with those of Jackson revealed that different states did not result in any evident discrepancies in BRS changes. Therefore, using anesthetized rats to evaluate the influence of fluvastatin on cardiac function and BRS is rational and clinically significant. Regardless of the unexpected $\triangle \mathrm{HR} / \triangle \mathrm{MABP}$ changes, fluvastatin still decreased the $\triangle \mathrm{HR} / \triangle \mathrm{MABP}$ increase back to the level of that in Ctr rats. Furthermore, the maximal HR responses to the maximal changes of MABP induced by various doses of PE or SNP were used as another indicator to estimate BRS. It can be concluded that fluvastatin could improve the significantly decreased maximal HR responses to the maximal changes of MABP in STZ-induced DM rats. According to recent reports, statins, including fluvastatin, exert a positive influence on the cardiovascular system not only by regulating blood lipids but also in a cholesterol-independent manner ${ }^{[34,35]}$. Tawfik et al demonstrated that simvastatin, a drug similar to fluvastatin, prevented impaired coronary endothelial cell-dependent vasorelaxation in 4-week STZ-induced diabetic rats ${ }^{[36]}$. Moreover, statins up-regulated neuronal nitric oxide synthase (nNOS) expression in the rostral ventrolateral medulla (RVLM), a vasomotor center in the brainstem, down-regulated sympathetic nerve activity and achieved an improvement in the $\mathrm{BRS}^{[37]}$. The nNOS mechanism responded relatively quickly and led to an improved BRS after $30 \mathrm{~d}$ of fluvastatin treatment. As discussed above, the exact mechanism by which fluvastatin was able to improve impaired BRS requires further study.

In our study, fluvastatin significantly ameliorated the impaired cardiac function and BRS in STZ-induced type 1 DM rats. The results were consistent with previously observed positive effects of long-term fluvastatin treatment in patients with coronary heart disease or undergoing coronary intervention $^{[38-40]}$. Because the parasympathomimetic activity reflected by the baroreflex activity in turn exerts an antiarrythmogenic effect counteracting the proarrhythmic effect of the sympathetic nervous system, the fluvastatin-ameliorated BRS can contribute to a reduction in cardiac mortality ${ }^{[38-41]}$. Undoubtedly, these findings will result in increased interest in the use of fluvastatin to treat diabetic patients with cardiac complications, and the mechanisms behind these effects deserve further study.

\section{Acknowledgements}

This study was financially supported by the National Natural Science Foundation of China (No 30870862), the Key Project of Natural Science Foundation of Heilongjiang Province (No ZJY0703-02), New Century Excellent Talents in University supported by the Ministry of Education of China (№ NCET08) and the Heilongjiang Postdoctoral Science Starting Foundation.

\section{Author contribution}

Jing AI, Li-hua SUN, and Bao-feng YANG designed the research and supervised the project; Fang XIE and Chao SUN established the diabetic model; Jing-yuan LI and Guan-yi LU measured food and drink intake; Chao SUN, Xin CHEN, and Hui CHE performed the animal studies, including the biochemical indexes of blood and the recording of blood pressure, HR and BRS; Jing AI, Fang XIE, and Chao SUN analyzed the data; Fang XIE and Jing AI wrote the manuscript; and Jing $\mathrm{AI}$ and Li-hua SUN revised the manuscript.

\section{References}

1 Rubler S, Dlugash J, Yuceoglu YZ, Kumral T, Branwood AW, Grishman A. New type of cardiomyopathy associated with diabetic glomerulosclerosis. Am J Cardiol 1972; 30: 595-602.

2 Vinik Al, Ziegler D. Diabetic cardiovascular autonomic neuropathy. Circulation 2007; 115: 387-97.

3 De Angelis K, Schaan BD, Maeda CY, Dall'Ago P, Wichi RB, Irigoyen MC. Cardiovascular control in experimental diabetes. Braz J Med Biol Res 2002; 35: 1091-100.

4 El-Menyar AA. Dysrhythmia and electrocardiographic changes in diabetes mellitus: pathophysiology and impact on the incidence of sudden cardiac death. J Cardiovasc Med (Hagerstown) 2006; 7: 580-5.

5 La Rovere MT, Pinna GD, Hohnloser SH, Marcus FI, Mortara A, Nohara $\mathrm{R}$, et al. Baroreflex sensitivity and heart rate variability in the identification of patients at risk for life-threatening arrhythmias: implications of clinical trials. Circulation 2001; 103: 2072-7.

6 Endo A, Kuroda M, Tanzawa K. Competitive inhibition of 3-hydroxy3-methylglutaryl coenzyme A reductase by ML-236A and ML-236B fungal metabolites, having hypocholesterolemic activity. FEBS Lett 1976; 72: 323-6.

7 Lawrence JM, Reckless JP. Fluvastatin. Expert Opin Pharmacother 2002; 3: 1631-41.

8 Christians U, Jacobsen W, Floren LC. Metabolism and drug interactions of 3-hydroxy-3-methylglutaryl coenzyme A reductase inhibitors in transplant patients: are the statins mechanistically similar? Pharmacol Ther 1998; 80: 1-34.

9 Corsini A, Bellosta S, Baetta R, Fumagalli R, Paoletti R, Bernini F. New insights into the pharmacodynamic and pharmacokinetic properties of statins. Pharmacol Ther 1999; 84: 413-28.

10 Corsini A, Jacobson TA, Ballantyne CM. Fluvastatin: clinical and safety profile. Drugs 2004; 64: 1305-23.

11 Perreault S, Hamilton VH, Lavoie F, Grover S. A head-to-head comparison of the cost effectiveness of HMG-CoA reductase inhibitors and fibrates in different types of primary hyperlipidemia. Cardiovasc Drugs Ther 1997; 10: 787-94.

12 Bellosta S, Ferri N, Arnaboldi L, Bernini F, Paoletti R, Corsinin A. Pleiotropic effects of statins in atherosclerosis and diabetes. Diabetes Care 2000; 23: B72-8.

13 Armpatzis CA, Goedhart D, Serruys PW, Saia F, Lemos PA, de Feyter P. Fluvastatin reduces the impact of diabetes on long-term outcome after coronary intervention - a Lescol Intervention Prevention Study (LIPS) substudy. Am Heart J 2005; 149: 329-35.

14 Matsuki A, Nozawa T, Igarashi N, Sobajima M, Ohori T, Suzuki T, et al. Fluvastatin attenuates diabetes-induced cardiac sympathetic neuropathy in association with a decrease in oxidative stress. Circ $J$ 2010; 74: 468-75.

15 Imaeda A, Aoki T, Kondo Y, Hori M, Ogata M, Obayashi H, et al. 
Protective effects of fluvastatin against reactive oxygen species induced DNA damage and mutagenesis. Free Radic Res 2001; 34 : 33-44.

16 Ai J, Yan X, Zhao L, Lu Y, Liang F, Cai B, et al. The protective effect of Daming capsule on heart function in streptozocin-induced diabetic rats with hyperlipidemia. Biol Pharm Bull 2009; 32: 1354-8.

17 Ai J, Liang F, Zhou H, Zhao J, Wang N, Zhu S, et al. Mechanism of impaired baroreflex sensitivity in Wistar rats fed a high-fat and -carbohydrate diet. Br J Nutr 2010; 104: 291-7.

18 Lin M, Liu R, Gozal D, Wead WB, Chapleau MW, Wurster R, et al. Chronic intermittent hypoxia impairs baroreflex control of heart rate but enhances heart rate responses to vagal efferent stimulation in anesthetized mice. Am J Physiol Heart Circ Physiol 2007; 293: H997-1006.

19 Patel KP, Zhang PL. Baroreflex function in streptozotocin (STZ) induced diabetic rats. Diabetes Res Clin Pract 1995; 27: 1-9.

20 Lin M, Ai J, Harden SW, Huang C, Li L, Wurster RD, et al. Impairment of baroreflex control of heart rate and structural changes of cardiac ganglia in conscious streptozotocin (STZ)-induced diabetic mice. Auton Neurosci 2010; 155: 39-48.

21 Dall'ago P, D'Agord Schaan B, da Silva Vo, Werner J, da Silva Soares $\mathrm{PP}$, de Angelis K, et al. Parasympathetic dysfunction is associated with baroreflex and chemoreflex impairment in streptozotocin-induced diabetes in rats. Auton Neurosci 2007; 131: 28-35.

22 Meyrelles SS, Mauad H, Mathias SC, Cabral AM, Vasquez EC. Effects of myocardial hypertrophy on neural reflexes controlling cardiovascular function. J Auton Nerv Syst 1998; 73: 135-42.

23 Itagaki M, Takaguri A, Kano S, Kaneta S, Ichihara K, Satoh K. Possible mechanisms underlying statin-induced skeletal muscle toxicity in L6 fibroblasts and in rats. J Pharamacol Sci 2009; 109: 94-101.

24 Basic-Jukic N, Kes P, Bubic-Filipi L, Vranjican Z. Rhabdomyolysis and acute kidney injury secondary to concomitant use of fluvastatin and rapamycin in a renal transplant recipient. Nephrol Dial Transplant 2010; 25: 2036; author reply 2036-7.

25 Chang KS, Lund DD. Alterations in the baroreceptor reflex control of heart rate in streptozotocin diabetic rats. J Mol Cell Cardiol 1986; 18 : 617-24.

26 Homma S, Yamazaki Y, Karakida T. Blood pressure and heart rate relationships during cervical sympathetic and vagus nerve stimulation in streptozotocin diabetic rats. Brain Res 1993; 629: 342-4.

27 Cohen AJ, McCarthy DM, Rossetti RR. Renin secretion by the spontaneously diabetic rat. Diabetes 1986; 35: 341-6.

28 Dall'Ago P, Fernandes TG, Machado UF, Belló AA, Irigoyen MC. Baroreflex and chemoreflex dysfunction in streptozotocin-diabetic rats. Braz J Med Biol Res 1997; 30: 119-24.
29 Maeda CY, Fernandes TG, Lulhier F, Irigoyen MC. Streptozotocin diabetes modifies arterial pressure and baroreflex sensitivity in rats. Braz J Med Biol Res 1995; 28: 497-501.

30 Heistad DD, Abboud FM, Mark AL, Schmid PG. Interaction of baroreceptor and chemoreceptor reflexes. Modulation of the chemoreceptor reflex by changes in baroreceptor activity. J Clin Invest 1974; 53: 1226-36.

31 Jackson CV, Carrier GO. Influence of short-term experimental diabetes on blood pressure and heart rate in response to norepinephrine and angiotensin II in the conscious rat. J Cardiovasc Pharmacol 1983; 5: 260-5.

32 Shimokawa A, Kunitake T, Takasaki M, Kannan H. Differential effects of anesthetics on sympathetic nerve activity and arterial baroreceptor reflex in chronically instrumented rats. J Auton Nerv Syst 1998; 72 : 46-54.

33 Van Leeuwen AF, Evans RG, Ludbrook J. Effects of halothane, ketamine, propofol and alfentanil anaesthesia on circulatory control in rabbits. Clin Exp Pharmacol Physiol 1990; 17: 781-98.

34 Maron DJ, Fazio S, Linton MF. Current perspectives on statins. Circulation 2000; 101: 207-13.

35 Liao JK. Isoprenoids as mediators of the biological effects of statins. J Clin Invest 2002; 110: 285-8.

36 Tawfik HE, El-Remessy AB, Matragoon S, Ma G, Caldwell RB, Caldwell RW. Simvastatin improves diabetes-induced coronary endothelial dysfunction. J Pharmacol Exp Ther 2006; 319: 386-95.

37 Gao L, Wang W, Zucker IH. Simvastatin inhibits central sympathetic outflow in heart failure by a nitric-oxide synthase mechanism. J Pharmacol Exp Ther 2008; 326: 278-85.

38 Ballantyne CM, Riegger G, Moore N, Saia F, Serruys PW. Fluvastatin reduces cardiac mortality in patients with coronary heart disease. Cardiovasc Drugs Ther 2004; 18: 67-75.

39 Riegger G, Abletshauser C, Ludwig M, Schwandt P, Widimsky J, Weidinger $\mathrm{G}$, et al. The effect of fluvastatin on cardiac events in patients with symptomatic coronary artery disease during one year of treatment. Atherosclerosis 1999; 144: 263-70.

40 Serruys PW, de Feyter P, Macaya C, Kokott N, Puel J, Vrolix M, et al. Fluvastatin for prevention of cardiac events following successful first percutaneous coronary intervention: a randomized controlled trial. JAMA 2002; 287: 3215-22.

41 Serruys PW, De Feyter PJ, Benghozi R, Hugenholtz PG, Lesaffre E. The Lescol(R) Intervention Prevention Study (LIPS): a doubleblind, placebo-controlled, randomized trial of the long-term effects of fluvastatin after successful transcatheter therapy in patients with coronary heart disease. Int J Cardiovasc Intervent 2001; 4: 165-72. 